\title{
An Analytical Model of Iceberg Drift $\mathscr{O}$
}

\author{
Till J. W. Wagner, Rebecca W. Dell, And IAN Eisenman \\ University of California, San Diego, La Jolla, California
}

(Manuscript received 2 December 2016, in final form 6 April 2017)

\begin{abstract}
The fate of icebergs in the polar oceans plays an important role in Earth's climate system, yet a detailed understanding of iceberg dynamics has remained elusive. Here, the central physical processes that determine iceberg motion are investigated. This is done through the development and analysis of an idealized model of iceberg drift. The model is forced with high-resolution surface velocity and temperature data from an observational state estimate. It retains much of the most salient physics, while remaining sufficiently simple to allow insight into the details of how icebergs drift. An analytical solution of the model is derived, which highlights how iceberg drift patterns depend on iceberg size, ocean current velocity, and wind velocity. A long-standing rule of thumb for Arctic icebergs estimates their drift velocity to be $2 \%$ of the wind velocity relative to the ocean current. Here, this relationship is derived from first principles, and it is shown that the relationship holds in the limit of small icebergs or strong winds, which applies for typical Arctic icebergs. For the opposite limit of large icebergs (length $>12 \mathrm{~km}$ ) or weak winds, which applies for typical Antarctic tabular icebergs, it is shown that this relationship is not applicable and icebergs move with the ocean current, unaffected by the wind. The latter regime is confirmed through comparisons with observed iceberg trajectories near the Antarctic Peninsula.
\end{abstract}

\section{Introduction}

Recent years have seen an increased interest in the fate of icebergs shed from high-latitude glaciers and ice shelves. They remain a threat to shipping as well as offshore oil and gas exploration. This is of particular relevance as retreating Arctic sea ice and increasing hydrocarbon demands have garnered the attention of industrial developers interested in both shipping and drilling in the Arctic Ocean (Pizzolato et al. 2014; Unger 2014; Henderson and Loe 2016). Concurrently, ongoing global climate change is being held responsible for an observed increase in calving fluxes from Antarctic and Greenland glaciers, an increase that is projected to accelerate during the coming decades (e.g., Rignot and Kanagaratnam 2006; Copland et al. 2007; Rignot et al. 2011; Joughin et al. 2014) and that is expected to impact regional ecosystems and oceanographic conditions (e.g., Vernet et al. 2012; Smith et al. 2013; Stern et al. 2015; Duprat et al. 2016). Furthermore, rapid shedding of

Supplemental information related to this paper is available at the Journals Online website: http://dx.doi.org/10.1175/ JPO-D-16-0262.s1.

Corresponding author: Till J. W. Wagner, tjwagner@ucsd.edu icebergs from Northern Hemisphere ice sheets during the Heinrich events of the last glacial period are believed to have affected oceanic and atmospheric conditions on a global scale [see reviews in Hemming (2004) and Stokes et al. (2015)].

In light of these factors, icebergs have recently begun to be implemented in state-of-the-art global climate models (GCMs; e.g., Martin and Adcroft 2010; Hunke and Comeau 2011; Stern et al. 2016) and Earth System Models of Intermediate Complexity (EMICs; e.g., Jongma et al. 2009, 2013; Bügelmayer et al. 2015a,b). An improved physical understanding of iceberg dynamics is important for this model development and will aid in the interpretation of the model simulation results.

Previous iceberg drift studies have often focused on the ability to (i) reproduce individual iceberg trajectories using comprehensive dynamic hindcast models (Smith and Banke 1983; Lichey and Hellmer 2001; Keghouche et al. 2009; Turnbull et al. 2015) or (ii) predict trajectories using statistical relationships derived from observed trajectories. A well-known feature of the latter approach is the empirical rule of thumb that icebergs move at approximately $2 \%$ of the wind velocity relative to the ocean current (e.g., Garrett et al. 1985; Smith and Donaldson 1987; Smith 1993; Bigg et al. 1997). Other studies have focused on large-scale 
freshwater release from icebergs into the high-latitude oceans (e.g., Bigg et al. 1997; Death et al. 2006; Martin and Adcroft 2010; Jongma et al. 2013; Roberts et al. 2014). These studies typically use a representation of iceberg drift that is based on the model introduced by Bigg et al. (1997).

Here, we examine the salient characteristics of how iceberg trajectories are determined. We develop an idealized iceberg drift model, which allows an analytical solution of the iceberg velocity as a function of the local water and air surface velocities. Because the iceberg trajectories are found to depend on iceberg size, we couple the drift model to an idealized decay model. This is adapted from the decay representation in the comprehensive iceberg model of Bigg et al. (1997). The Lagrangian iceberg model presented here is computationally inexpensive and requires only three input fields to simulate iceberg trajectories: ocean and atmosphere surface velocities and sea surface temperature (SST). Furthermore, the somewhat idealized formulation of the model facilitates detailed physical interpretation and helps build understanding of the processes that determine iceberg drift.

This article is structured as follows: Section 2 introduces the iceberg drift and decay representations as well as the analytical solution for the drift velocity. Section 3 presents iceberg trajectories that are computed from the analytical solution, with surface conditions taken from an observational state estimate. Section 4 discusses the role winds and currents play in determining iceberg trajectories, focusing on the limits of small icebergs (Arctic) and large icebergs (Antarctic). Concluding remarks are given in section 5 .

\section{Iceberg drift model}

\section{a. Governing equation for iceberg drift}

We develop an iceberg drift model that is adapted from the canonical family of drift models introduced by Bigg et al. (1997) and used by Gladstone et al. (2001), Martin and Adcroft (2010), Marsh et al. (2015), and other studies. These models mostly differ only in minor details, and the momentum equation is typically written in the form

$$
M \frac{d \mathbf{v}_{i}}{d t}=-M f \hat{\mathbf{k}} \times \mathbf{v}_{i}+F_{p}+F_{w}+F_{a}+F_{r}+F_{i},
$$

where $M$ is the mass of the iceberg, $\mathbf{v}_{i}$ is the iceberg velocity, and $f$ is the Coriolis parameter, which varies with latitude. The terms on the right-hand side represent Coriolis force $M f \hat{\mathbf{k}} \times \mathbf{v}_{i}$, pressure gradient force $F_{p}$, water drag $F_{w}$, air drag $F_{a}$, wave radiation force $F_{r}$, and sea ice drag $F_{i}$.
The model developed in this study retains the main components of previous formulations. It is, however, somewhat idealized, with the central approximations being as follows:

1) The acceleration term $M d \mathbf{v}_{i} / d t$ is neglected in Eq. (1) based on the expectation that it is much smaller than other terms in the momentum balance (e.g., Crepon et al. 1988).

2) The pressure gradient force is approximated from the ocean velocity by assuming geostrophic ocean currents.

3) The iceberg speed $\left|\mathbf{v}_{i}\right|$ is taken to be much smaller than the surface wind speed $\left|\mathbf{v}_{a}\right|$.

4) The drag forces from sea ice and wave radiation are neglected based on the expectation that they are a small component of the momentum balance.

5) The water drag is approximated based on the ocean current velocity at the surface alone, neglecting vertical variations in the current over the depth of the iceberg. Similarly, the wind felt by the iceberg at any height is approximated to be equal to the surface wind.

The justification for each approximation is given below.

Approximation 1: This approximation is best satisfied for small icebergs. Using the model simulations of section 3 (below), we find that this approximation is typically fairly well satisfied for Arctic icebergs. When the iceberg length is less than $1.5 \mathrm{~km}$, we find that $M d \mathbf{v}_{i} / d t$ estimated from the simulated velocities is typically less than $10 \%$ of the air drag term. For very large icebergs, such as those in the Antarctic, this approximation begins to break down; for lengths of about $20 \mathrm{~km}$, the magnitude of the acceleration term is typically similar to the air drag term. However, when the model is solved numerically both with and without the inclusion of the acceleration term, we find that approximation 1 ultimately has relatively little influence on typical iceberg trajectories for both small and large icebergs (supplemental material Figs. S1 and S2).

Approximation 2: The pressure gradient force has previously been argued to be well approximated by assuming a geostrophic ocean velocity (Smith and Banke 1983; Gladstone et al. 2001; Stern et al. 2016). It should be noted, however, that Bigg et al. (1996) found that this approximation may introduce substantial errors in regions where the ageostrophic component of the ocean velocity is large.

Approximation 3: While the typical velocity scale of surface winds is $\left|\mathbf{v}_{a}\right| \sim 10 \mathrm{~m} \mathrm{~s}^{-1}$, icebergs tend to travel at speeds $\left|\mathbf{v}_{i}\right| \sim 0.1 \mathrm{~m} \mathrm{~s}^{-1}$ (Robe 1980), such that typically $\left|\mathbf{v}_{i}\right| /\left|\mathbf{v}_{a}\right| \sim 0.01$.

Approximation 4: Previous studies have either modeled wave radiation explicitly (e.g., Bigg et al. 1996, 


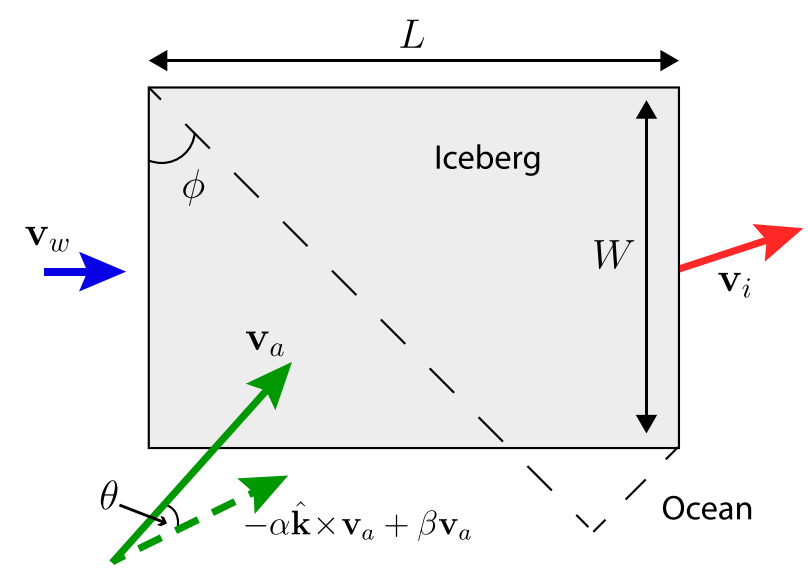

FIG. 1. Bird's eye view schematic of the horizontal surface air velocity (green arrow) and water velocity (blue arrow) driving the iceberg motion (red arrow). The wind-driven component of the iceberg velocity $\alpha \hat{\mathbf{k}} \times \mathbf{v}_{a}+\beta \mathbf{v}_{a}$, which acts at an angle $\theta=\tan ^{-1}(\alpha / \beta)$ to the wind, is also indicated (dashed green arrow). In this schematic the water drag is acting along the distance $W$, and the air drag is acting along the cross-sectional length $W \cos \phi+L \sin \phi$ (long dashed line). We average over all orientations in the model, effectively taking the orientation to be random.

1997; Death et al. 2006; Jongma et al. 2009) or included it in the wind drag term where it alters the drag coefficient (Smith 1993; Keghouche et al. 2009). However, a number of studies have found that the contribution of wave radiation is typically small compared to the air and water drag terms (Bigg et al. 1997; Gladstone et al. 2001). Hence, for simplicity, we neglect the wave radiation term. We also neglect the sea ice drag term, which allows us to model the motion of icebergs outside of the central sea ice pack. Icebergs can spend long periods of time locked-in by sea ice in regions with heavy sea ice, such as north of Greenland and in the Weddell Sea (Lichey and Hellmer 2001; Schodlok et al. 2006). Neglecting sea ice drag also omits the seasonality in iceberg drift and decay associated with the large seasonal cycle of the polar sea ice cover. The drift model developed here will hence have limited applicability for regions and periods with high sea ice concentration.

Approximation 5: Vertical variations of the currents and winds near the surface are neglected for simplicity, as in most previous studies (e.g., Bigg et al. 1997; Jongma et al. 2009; Martin and Adcroft 2010). This approximation limits the applicability of the model for predicting the trajectories of icebergs in regions with large vertical shear in the ocean currents or winds. We note that some iceberg models include an explicit representation of this vertical structure (e.g., Kubat et al. 2005; Turnbull et al. 2015; Merino et al. 2016; FitzMaurice et al. 2016).
The water and air drag terms are given by

$$
\begin{gathered}
F_{w}=\tilde{C}_{w}\left|\mathbf{v}_{w}-\mathbf{v}_{i}\right|\left(\mathbf{v}_{w}-\mathbf{v}_{i}\right), \\
F_{a}=\tilde{C}_{a}\left|\mathbf{v}_{a}-\mathbf{v}_{i}\right|\left(\mathbf{v}_{a}-\mathbf{v}_{i}\right),
\end{gathered}
$$

where $\tilde{C}_{w} \equiv(1 / 2) \rho_{w} C_{w} A_{w}$ and $\tilde{C}_{a} \equiv(1 / 2) \rho_{a} C_{a} A_{a}$. Here, $C_{w}$ and $C_{a}$ are bulk drag coefficients of water and air, $\rho_{w}$ and $\rho_{a}$ are water and air densities, and $A_{w}$ and $A_{a}$ are the cross-sectional areas on which the water and air velocities act, respectively. We take the icebergs to be cuboids of height $H$, length $L$, and width $W$ (Fig. 1), and we only consider drag exerted on the vertical surfaces of the icebergs. Previous studies have typically assumed a fixed orientation of the iceberg relative to the wind and current (e.g., Bigg et al. 1997). We instead adopt the approximation that icebergs are oriented at a random angle $\phi$ relative to the wind and current. In this case, the long-term mean horizontal length of the vertical working surface area for both drag terms is $(2 / \pi) \int_{0}^{\pi / 2}(W \cos \phi+L \sin \phi) d \phi=(2 / \pi)(L+W)$, such that

$$
A_{w}=\frac{\rho_{i}}{\rho_{w}} \frac{2}{\pi}(L+W) H, \quad A_{a}=\frac{\left(\rho_{w}-\rho_{i}\right)}{\rho_{i}} A_{w} .
$$

The pressure gradient force is defined as $F_{p} \equiv-\left(M / \rho_{w}\right) \nabla P$, where $\nabla P$ is the horizontal pressure gradient due primarily to sea surface slope. Approximating that the pressure gradient force acting on the icebergs arises only from the geostrophic component of ocean flow (approximation 2) allows us to write the pressure force as $F_{p}=M f \hat{\mathbf{k}} \times \mathbf{v}_{w}$. The first two terms in Eq. (1) can then be combined.

Making use of approximations 1-5 leads to

$$
0=M f \hat{\mathbf{k}} \times \Delta \mathbf{v}+\tilde{C}_{w}|\Delta \mathbf{v}| \Delta \mathbf{v}+\tilde{C}_{a}\left|\mathbf{v}_{a}\right| \mathbf{v}_{a}
$$

where we have used that $\mathbf{v}_{a}-\mathbf{v}_{i} \simeq \mathbf{v}_{a}$ (approximation 3) and defined $\Delta \mathbf{v} \equiv \mathbf{v}_{w}-\mathbf{v}_{i}$. Here, $\mathbf{v}_{w}$ and $\mathbf{v}_{a}$ are approximated by the surface velocities (approximation 5).

The importance of the terms in Eq. (3) can be quantified by introducing dimensionless quantities

$$
\Lambda_{w} \equiv \frac{\tilde{C}_{w}|\Delta \mathbf{v}|}{M f} \quad \text { and } \quad \Lambda_{a} \equiv \frac{\tilde{C}_{a}\left|\mathbf{v}_{a}\right|^{2}}{M f|\Delta \mathbf{v}|},
$$

which describe the magnitudes of the water and air drag terms relative to the Coriolis term, respectively. Note that these quantities are both analogous to the Ekman number for fluid flows.

Equation (3) can then be simplified to 


$$
0=\hat{\mathbf{k}} \times \Delta \hat{\mathbf{v}}+\Lambda_{w} \Delta \hat{\mathbf{v}}+\Lambda_{a} \hat{\mathbf{v}}_{a},
$$

with unit vectors $\Delta \hat{\mathbf{v}} \equiv \Delta \mathbf{v} /|\Delta \mathbf{v}|$ and $\hat{\mathbf{v}}_{a} \equiv \mathbf{v}_{a} /\left|\mathbf{v}_{a}\right|$.

\section{b. Analytical solution}

Equation (5) contains $\mathbf{v}_{i}$ in the quantities $\Delta \hat{\mathbf{v}}, \Lambda_{w}$, and $\Lambda_{a}$. Note that this vector equation can be written as a set of two coupled scalar algebraic equations, which are nonlinear in the components of $\mathbf{v}_{i}$. Equation (5) can be solved analytically for $\mathbf{v}_{i}$, giving as a solution

$$
\mathbf{v}_{i}=\mathbf{v}_{w}+\gamma\left(-\alpha \hat{\mathbf{k}} \times \mathbf{v}_{a}+\beta \mathbf{v}_{a}\right) .
$$

Here, $\gamma$ is a dimensionless parameter, which describes the relative importance of water drag versus air drag:

$$
\gamma \equiv \sqrt{\frac{\tilde{C}_{a}}{\tilde{C}_{w}}}=\left[\frac{\rho_{a}\left(\rho_{w}-\rho_{i}\right)}{\rho_{w} \rho_{i}} \frac{C_{a}}{C_{w}}\right]^{1 / 2} .
$$

The dimensionless parameters $\alpha$ and $\beta$ in Eq. (6) are

$$
\begin{aligned}
& \alpha \equiv \frac{1}{2 \Lambda^{3}}\left(\sqrt{1+4 \Lambda^{4}}-1\right), \\
& \beta \equiv \frac{1}{\sqrt{2} \Lambda^{3}}\left[\left(1+\Lambda^{4}\right) \sqrt{1+4 \Lambda^{4}}-3 \Lambda^{4}-1\right]^{1 / 2},
\end{aligned}
$$

where

$$
\Lambda \equiv \sqrt{\Lambda_{w} \Lambda_{a}}=\frac{\gamma C_{w}}{\pi f} \frac{\left|\mathbf{v}_{a}\right|}{S}
$$

with $S \equiv L W /(L+W)$ being the harmonic mean horizontal length of the iceberg. Since the Coriolis parameter does not vary substantially along the simulated iceberg trajectories, the variable $\Lambda$ can be approximately interpreted as the ratio of wind speed to iceberg size scaled by several constants.

From Eq. (6) we see that the wind drives icebergs at an angle $\theta \equiv \tan ^{-1}(\alpha / \beta)$. How $\theta$ varies with $\Lambda$ will be discussed further in section 4 . Note that the iceberg velocity is independent of iceberg height $H$ since the drag terms and the Coriolis term both scale linearly with $H$, and only the ratios of these terms feature in Eq. (5).

\section{c. Iceberg decay model}

Iceberg motion is affected by the decay of the iceberg, since the coefficients $\alpha$ and $\beta$ depend on the iceberg length $S$. Iceberg decay is modeled here using a modified version of the thermodynamic decay model developed by Bigg et al. (1997). This model accounts for three melt processes: (i) wind-driven wave erosion, (ii) turbulent basal melt, and (iii) sidewall erosion from buoyant convection. The main difference between the present model and that of Bigg et al. (1997) is that we use a different iceberg rollover criterion because the rollover criterion used by Bigg et al. (1997), which was adopted from Weeks and Mellor (1978), has been found to contain several errors Wagner et al. 2017, manuscript submitted to Ocean Modell.). The decay model is described in more detail in the appendix.

\section{Model validation using ECCO2 output}

The model is forced using the NASA ECCO2 product, a global ocean state estimate of the period 1992-2012 that is obtained using satellite and in situ data in concert with an ocean general circulation model (Menemenlis et al. 2008). The surface wind forcing in ECCO2 is taken from the Japanese 25-year Reanalysis Project (JRA-25; Onogi et al. 2007). For simplicity we idealize the icebergs to be noninteracting passive Lagrangian particles. This allows the efficient computation of large numbers of iceberg trajectories.

We consider two scenarios:

(a) small icebergs $(L<1.5 \mathrm{~km})$ released from three main outlet glaciers in Greenland; and

(b) large tabular icebergs $(L>15 \mathrm{~km})$ released off the coast of the Antarctic Peninsula.

The upper size limit of the Greenland icebergs was chosen to correspond to that used by Bigg et al. (1997) and subsequent studies. The size limit of the Antarctic icebergs is similar to the lower bound of icebergs tracked by the National Ice Service [which is 10 nautical miles ( $\mathrm{n} \mathrm{mi} ; 1 \mathrm{n} \mathrm{mi}=1.852 \mathrm{~km})$ ], and it is 10 times the size of the largest Arctic icebergs simulated in scenario a.

The ECCO2 dataset, which is used for both scenarios, consists of output fields averaged over 3-day intervals. We compute iceberg trajectories using Eq. (6) coupled to the decay model described in section $2 \mathrm{c}$. This requires as input the ECCO2 surface water velocities and JRA25 surface wind velocities as well as the sea surface temperature. The wind velocities, which are given on a $1^{\circ} \times 1^{\circ}$ horizontal grid, are interpolated onto the $0.25^{\circ} \times$ $0.25^{\circ}$ grid of the ocean fields.

We integrate the iceberg trajectories using a forward Euler time-stepping scheme with 1-day temporal resolution. The 3-day ECCO2 and JRA-25 fields are linearly interpolated from time interval centers onto a 1-day time resolution to match the time stepping. Iceberg velocities are computed at each time step using currents and winds from the spatial grid box that is centered nearest to the iceberg location.

Grounding events are not resolved explicitly; instead we set iceberg velocities to zero when icebergs come within one grid box of land until the surface circulation 

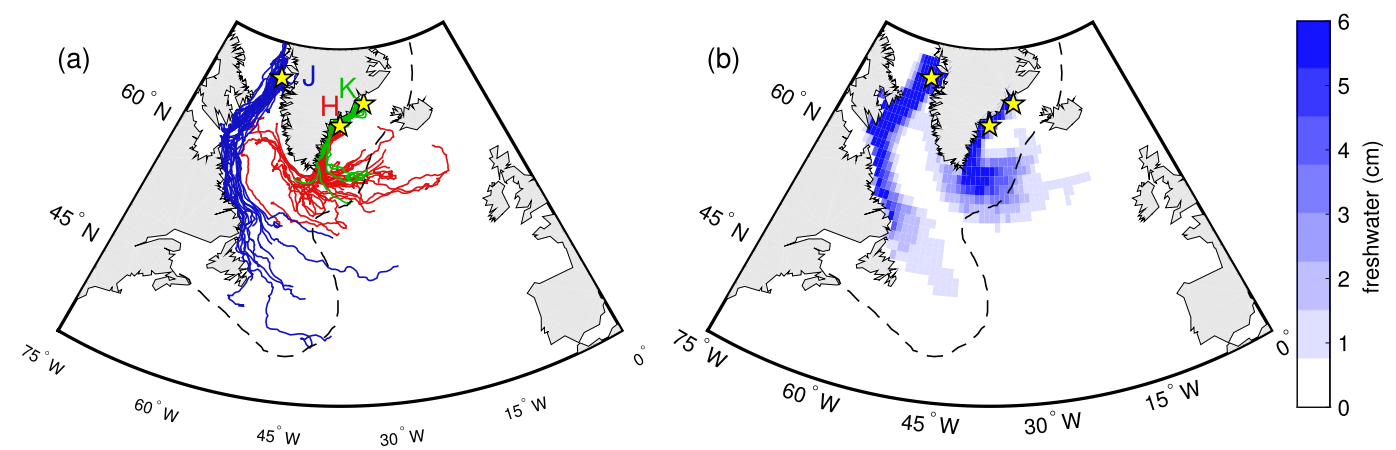

FIG. 2. Arctic iceberg trajectories. (a) Drift trajectories for 50 icebergs released at each of three Greenland outlet glaciers: Kangerlussuaq (K; green), Helheim ( $\mathrm{H}$; red), and Jakobshavn ( $\mathrm{J}$; blue). Iceberg release locations are indicated by yellow stars. The dashed line indicates the observed "normal" range of icebergs as given by the International Ice Patrol (2009). (b) Freshwater flux [centimeters per $250 \mathrm{~km}^{3}$ ice volume released, which corresponds to approximately half the total yearly ice volume released from calving around all of Greenland (Enderlin et al. 2014)].

moves them away from the coast, akin to schemes used previously (e.g., Wiersma and Jongma 2010).

\section{a. Arctic iceberg simulations}

We release Arctic icebergs near the outlets of three main Greenland ice discharge glaciers: Helheim, Kangerlussuaq, and Jakobshavn (Fig. 2). For each iceberg, the release location is chosen randomly from the centers of a $4 \times 4$ grid of ECCO2 grid points near each fjord outlet. Icebergs are released at random times within the first 3 years (1992-94) of the ECCO2 dataset and advected until they melt completely. This time period is sufficiently long to produce a relatively converged freshwater distribution. We consider 10 initial iceberg sizes (Table S1), with dimensions ranging from $100 \times$ $67 \times 67$ to $1500 \times 1000 \times 300 \mathrm{~m}^{3}$, similar to the classification of Bigg et al. (1997). A total of 500 icebergs are released for each size class from each glacier.

Figure 2a shows 50 iceberg trajectories for each of the three glaciers. Size classes and release dates for these trajectories are chosen at random. We find that most icebergs from Kangerlussuaq Glacier drift close to the coast southward in the East Greenland Current, with frequent groundings. Small icebergs from Helheim Glacier are commonly deflected eastward by winds once they are subject to the strong westerlies near the southern tip of Greenland. The larger Helheim icebergs remain more commonly in the coastal current, drift around the tip of Greenland, and subsequently make their way north (sizes are not indicated in Fig. 2). Icebergs from Jakobshavn, on the other hand, quickly make their way across Baffin Bay and follow the "Iceberg Alley" south along the Labrador coast toward Newfoundland. They mostly melt completely by the time they reach the Grand Banks (approximately $45^{\circ} \mathrm{N}, 50^{\circ} \mathrm{W}$ ). However, some simulated icebergs survive substantially longer and drift beyond the commonly observed iceberg boundary as estimated by the International Ice Patrol (2009), which is indicated by a dashed line in Fig. 2. This may be partially due to the decay model not accounting for the breakup of large icebergs, which is likely a dominant driver of large iceberg deterioration (e.g., Wagner et al. 2014; Tournadre et al. 2016), but for which an adequate model representation is still missing. Furthermore, some studies have added a temperature dependence to the parameterization of wind-driven wave erosion (e.g., Gladstone et al. 2001; Martin and Adcroft 2010), which causes faster decay in warmer waters, although others have not (e.g., Jongma et al. 2009; Bügelmayer et al. 2015a).

Figure $2 b$ shows the simulated freshwater input distribution due to iceberg melt. This is computed by averaging over all icebergs within each size class and then weighting each iceberg size class field according to the lognormal distribution used in Bigg et al. (1997, their Table 1) and subsequent studies. Considering the substantial simplifications of the present simulations, the resulting meltwater distribution is in fairly good agreement with those of Martin and Adcroft (2010, their Fig. 2b) and Marsh et al. (2015, their Fig. 3), although the eastward transport of freshwater from east Greenland icebergs is somewhat exaggerated here.

\section{b. Antarctic iceberg simulations}

We qualitatively validate the model against Antarctic tabular icebergs using the observed trajectories of large icebergs as catalogued in the Antarctic Iceberg Tracking Database. Figure 3a shows QuikSCAT/SeaWinds scatterometer observations (Ballantyne and Long 2002), the 


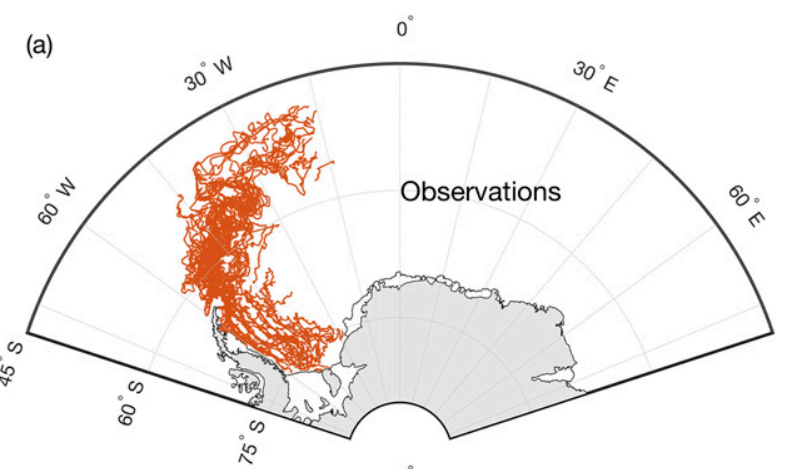

(b)

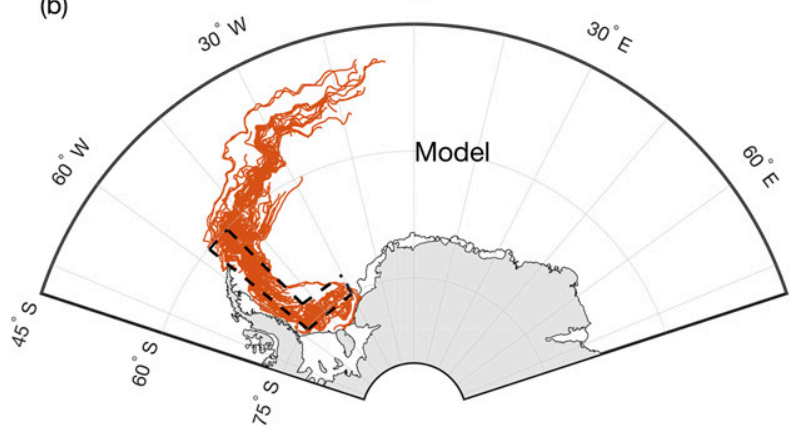

FIG. 3. Antarctic iceberg trajectories. (a) Observed iceberg trajectories from the Antarctic Iceberg Tracking Database, which is derived from QuikSCAT/SeaWinds scatterometer data (Ballantyne and Long 2002). Here, only the trajectories of icebergs with inception points around the Antarctic Peninsula are included. (b) Simulated trajectories during 1 year for 200 large icebergs $(L=$ 15-20 km), computed using Eq. (6) with ECCO2 input fields. Icebergs are released from random locations within the dashed polygon region.

full dataset of which tracked 352 icebergs, mostly of diameter $>10 \mathrm{~nm}$, over the years 1999-2009.

Using the model described in Eq. (6), we release 200 large icebergs of lengths between 15 and $20 \mathrm{~km}$ in the ECCO2 fields off the east coast of the Antarctic Peninsula and locations in the Weddell Sea and track these icebergs for 1 year (Fig. 3b).

Note that we ignore the drag and reduced melting effects of sea ice in these simulations (approximation 4 ). The large uncertainties inherent in this comparison should be emphasized. Iceberg release locations, iceberg dimensions, and drift periods are among the unconstrained factors that make a direct comparison between model output and satellite observations difficult. Considering these uncertainties, the simulated trajectories show fairly good agreement with observations, accurately capturing the general drift pattern along the east coast of the Antarctic Peninsula and into the Antarctic Circumpolar Current. Furthermore, the corresponding simulated meltwater distribution (not shown) compares reasonably well to that derived from observations by Silva et al. (2006). It should be noted by caveat that the iceberg trajectories shown in Fig. $3 b$ do not terminate with the disappearance of the icebergs but rather with the end of the 1-yr time window. Large tabular icebergs in these simulations would survive considerably longer, which is expected to be mainly an artifact of the model not accounting for breakup processes as well as the omission of an SST dependence in the wave erosion term, as discussed above.

\section{The role of winds and currents}

Here, we address the roles that the three terms in Eq. (6) play in determining iceberg trajectories. Specifically, we focus on the following questions:

- Are icebergs primarily driven by winds or by currents? To what degree does this depend on iceberg size and on the magnitude of the air and water velocities?

- What determines how much the wind drives icebergs in along-wind versus across-wind directions? In other words, how does the angle $\theta$ depend on the surface velocities and iceberg size?

To address these questions, we consider first the analytical solution (section 4a) and subsequently the iceberg trajectories and velocities that were numerically computed using ECCO2 (section $4 \mathrm{~b}$ ). Note that other factors, including iceberg shape and tangentially acting drag (Crepon et al. 1988), are also expected to affect the answers to the questions above, but these factors are beyond the scope of the present study.

\section{a. Winds and currents in the analytical solution}

\section{1) DIRECTION OF WIND-DRIVEN MOTION}

The Coriolis term in Eq. (3) causes some of the wind drag to project onto the direction perpendicular to the wind velocity, giving rise to the cross-product term in Eq. (6), which is somewhat analogous to Ekman transport. The importance of this term relative to the along-wind term can be assessed by considering the coefficients $\alpha$ and $\beta$ (Fig. 4). We compute firstorder series expansions of $\alpha$ and $\beta$ for small and large $\Lambda$ :

$$
\alpha \simeq\left\{\begin{array} { l l } 
{ \Lambda } & { \text { for } \Lambda \ll 1 , } \\
{ 1 / \Lambda } & { \text { for } \Lambda \gg 1 , }
\end{array} \quad \beta \simeq \left\{\begin{array}{ll}
\Lambda^{3} & \text { for } \Lambda \ll 1 \\
1 & \text { for } \Lambda \gg 1
\end{array}\right.\right.
$$

These asymptotics are included in Fig. 4. Note that since $\Lambda \propto\left|\mathbf{v}_{a}\right| / S$ is a measure of wind speed relative to iceberg 


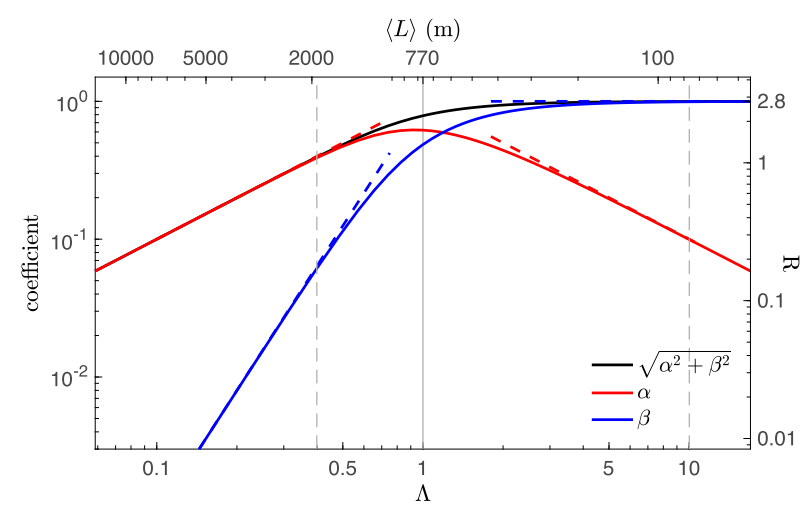

FIG. 4. (a) Coefficients $\alpha$ and $\beta$, as well as $\left(\alpha^{2}+\beta^{2}\right)^{1 / 2}$, plotted using $\log -\log$ coordinates. The asymptotics of Eq. (10) are shown as dashed lines. The critical value $\Lambda=1$ (gray vertical line) and the regimes for $\alpha / \beta<0.1$ and $\beta / \alpha<0.1$ (gray dashed lines) are also indicated. The top horizontal axis shows the iceberg length scale $\langle L\rangle$, as given by Eq. (13), using the average wind felt by simulated Arctic icebergs $\left(\left|\mathbf{v}_{a}\right|=5.7 \mathrm{~m} \mathrm{~s}^{-1}\right)$. The right vertical axis shows the coefficient $R$ of Eq. (14), quantifying the relative importance of wind forcing vs ocean current forcing.

size, these limits can arise in two different ways: $\Lambda \gg 1$ can apply to strong winds or alternatively to small icebergs. Similarly, $\Lambda \ll 1$ applies to weak winds or large icebergs.

The angle $\theta$, at which the surface winds drive the iceberg (relative to the direction of the wind), is indicated schematically in Fig. 1, and its dependence on $\Lambda$ is shown in Fig. 5. From Eq. (10), we obtain the asymptotic limits for the ratio $\alpha / \beta=\tan \theta$ :

$$
\frac{\alpha}{\beta} \simeq \begin{cases}\Lambda^{-2} & \text { for } \Lambda \ll 1 \\ \Lambda^{-1} & \text { for } \Lambda \gg 1\end{cases}
$$

Both the angle $\theta$ and the ratio $\alpha / \beta$ decrease monotonically with increasing $\Lambda$ : the stronger the wind blows, the more it drives the iceberg in the direction of the wind. The two asymptotic regimes meet when $\alpha=\beta$, in which case $\Lambda=1$ and $\theta=45^{\circ}$. Figure 5 shows that these asymptotic solutions provide a reasonably close approximation to the exact solution in the full range of $\Lambda$. For strong winds, $\alpha / \beta \ll 1$ (or equivalently $\Lambda \gg 1$ ), and we find that $\theta \rightarrow 0$; that is, the wind drives icebergs in the direction that it blows. For weak winds, on the other hand, $\alpha / \beta \ll 1$, and the icebergs move at $\theta \simeq 90^{\circ}$ to the wind. We conclude that icebergs drift primarily in the along-wind direction relative to the ocean currents when $\Lambda>1$ and across wind when $\Lambda<1$. Next, we consider these limits in more detail.

\section{(i) $\Lambda \gg 1$ (strong winds, small icebergs)}

From Eq. (10), we find that for strong winds or small icebergs the across-wind component of iceberg drift approaches zero, since $\alpha \rightarrow 0$, and the along-wind

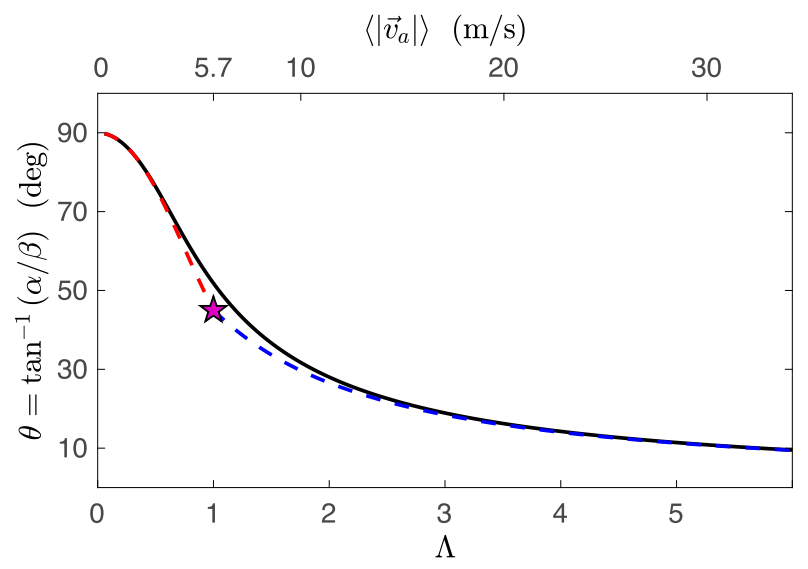

FIG. 5. The direction in which the wind drives icebergs $\theta$ as a function of the dimensionless wind speed $\Lambda$ (solid). The dashed curves show the asymptotic approximations for small and large $\Lambda$, which are given in Eq. (11). The point where these asymptotics meet, $\Lambda=1, \theta=45^{\circ}$, is indicated by the purple star. The upper horizontal axis indicates the wind speed from Eq. (13) using an iceberg of size of $L=770 \mathrm{~m}$.

component approaches a constant value, with $\beta \rightarrow 1$ (Fig. 4). Equation (6) therefore reduces to

$$
\mathbf{v}_{i}=\mathbf{v}_{w}+\gamma \mathbf{v}_{a} .
$$

Using density values $\rho_{a}=1.2 \mathrm{~kg} \mathrm{~m}^{-3}, \rho_{w}=1027 \mathrm{~kg} \mathrm{~m}^{-3}$, and $\rho_{i}=850 \mathrm{~kg} \mathrm{~m}^{-3}$ and taking bulk coefficients $C_{a}=0.9$ and $C_{w}=1.3$ (Bigg et al. 1997), we find from Eq. (7) that $\gamma=0.018$.

This is in close agreement with previous observational estimates, which have found the empirical rule of thumb that icebergs typically drift at approximately $2 \%$ of the wind velocity relative to the water. Such empirical estimates include $\gamma=0.018 \pm 0.7$ (Garrett et al. 1985) and $\gamma=0.017$ (Smith 1993), translating the previous results into the formalism of the present study. Here, by contrast, $\gamma=0.018$ is derived analytically from physical first principles.

These results not only shed light on the origin of this empirical rule of thumb, but they also provide constraints on its validity; icebergs satisfy the $2 \%$ rule only when $\Lambda \gg 1$. We can interpret this dimensionally in terms of iceberg size. Assuming a constant midlatitude Coriolis parameter $f=10^{-4} \mathrm{~s}^{-1}$ and a typical aspect ratio $L / W=1.5$ (Bigg et al. 1997), Eq. (9) becomes

$$
\Lambda \simeq c\left|\mathbf{v}_{a}\right| / L
$$

where $c=130 \mathrm{~s}$. This means that the limit $\Lambda \gg 1$ is satisfied when

$$
\left|\mathbf{v}_{a}\right| \gg L / c
$$


We conclude that the $2 \%$ rule is a good approximation for iceberg drift only when the length of the iceberg is sufficiently small or the surface wind speed is sufficiently large or the length of the iceberg is sufficiently small. In section $4 \mathrm{~b}$, we will consider how this relates to the simulated icebergs.

\section{(ii) $\Lambda \ll 1$ (weak winds, large icebergs)}

In this limit, the icebergs move in the direction perpendicular to the wind velocity, relative to the ocean current. The reason for this is contained in Eq. (6): the across-wind term is dominant for large icebergs since in this limit, the Coriolis force, which gives rise to the acrosswind component and scales with mass $M$, is large relative to the drag forces, which scale with cross-sectional area.

\section{2) SURFACE WINDS VERSUS CURRENTS}

In the limit of small $\Lambda$, both $\alpha$ and $\beta$ decrease when $\Lambda$ decreases. This implies that the total wind contribution to iceberg motion drops off for low winds or large icebergs. This is a further consequence of the Coriolis term growing large, since it depends only on $\mathbf{v}_{w}$ (and not $\mathbf{v}_{a}$ ). Large tabular icebergs (as occur mostly in Antarctica) can therefore be approximated to be driven by the ocean currents alone, $\mathbf{v}_{i}=\mathbf{v}_{w}$ as we confirm in section $4 \mathrm{~b}$ below.

The relative importance of wind and ocean currents can be quantified in terms of the ratio of the associated speeds. Previous studies have stated either that the water drag dominates (Matsumoto 1996) or that water and air drags are of similar magnitude (Gladstone et al. 2001). Here, we establish this relative importance quantitatively. We define the ratio of the magnitudes of the wind-driven and ocean-driven velocity components in Eq. (6) as

$$
R \equiv \gamma\left(\alpha^{2}+\beta^{2}\right)^{1 / 2}\left|\mathbf{v}_{a}\right| /\left|\mathbf{v}_{w}\right| .
$$

We will see below that the ratio $\left|\mathbf{v}_{a}\right| /\left|\mathbf{v}_{w}\right|$ is approximately constant for icebergs from a given region. This implies that small icebergs (with $\alpha^{2}+\beta^{2} \simeq 1$ ) move predominantly with the wind (i.e., $R>1$ ) when $\left|\mathbf{v}_{a}\right| /\left|\mathbf{v}_{w}\right|>1 / \gamma \simeq 50$. For very large icebergs, the water velocities (i.e., the denominator in $R$ ) will always be dominant, since in that case $\alpha^{2}+\beta^{2} \rightarrow 0$ (Fig. 4). In the following, we compare these limits to the actual velocity ratios experienced by icebergs simulated with the ECCO2 surface conditions.

\section{b. Wind, current, and iceberg velocities from simulations with ECCO2}

\section{1) Arctic iceberg Simulations}

A single 3-day snapshot (1-3 Jan 1993) of the ECCO2 velocities is shown in Fig. 6. Also shown is the wind-driven component of iceberg velocities $\gamma\left(-\alpha \hat{\mathbf{k}} \times \mathbf{v}_{a}+\beta \mathbf{v}_{a}\right)$ and its magnitude $\gamma\left(\alpha^{2}+\beta^{2}\right)^{1 / 2}\left|\mathbf{v}_{a}\right|$ for iceberg size classes 1 and 10 (second row). The third row of Fig. 6 represents the corresponding iceberg velocity fields.

In agreement with the discussion above, we find that (i) the wind-driven component is stronger for smaller icebergs and (ii) that its direction is closely aligned with that of $\mathbf{v}_{a}$ for small icebergs but not for large icebergs. Figure 6 shows that the iceberg velocity field of the small size class is largely determined by the wind field, while the larger icebergs move primarily with the ocean.

The relative importance of each of the three terms in Eq. (6) for the motion of Arctic icebergs can be quantified using the mean current and wind speeds experienced by the icebergs along their trajectory. These wind speeds are shown in Fig. S3. For a given glacier, the wind speed is found to be approximately constant, with the two east Greenland glaciers (Helheim and Kangerlussuaq) experiencing higher wind speeds $\left(\simeq 6.5 \mathrm{~m} \mathrm{~s}^{-1}\right)$ and Jakobshavn having lower wind speeds $\left(\simeq 4 \mathrm{~m} \mathrm{~s}^{-1}\right)$.

First, we consider the relative importance of the two wind-forced terms in Eq. (6). Inserting the average value of $\left|\mathbf{v}_{a}\right|=5.7 \mathrm{~m} \mathrm{~s}^{-1}$ for all Arctic icebergs into Eq. (13) gives $L=770 \mathrm{~m} / \Lambda$. This length scale, indicated as the top horizontal axis of Fig. 4, acts as a measure of the relative strength of the across-wind and along-wind terms in Eq. (6). The critical length corresponding to $\Lambda=1, L^{*} \equiv 770 \mathrm{~m}$, separates the regimes where $\alpha$ and $\beta$ dominate. This means that Arctic icebergs will be driven mostly along wind if $L<L^{*}$ and mostly across wind if $L>L^{*}$. Alternatively, an iceberg of size $L=770 \mathrm{~m}$ will move primarily across wind for $\left|\mathbf{v}_{a}\right|<5.7 \mathrm{~m} \mathrm{~s}^{-1}$ and along wind for $\left|\mathbf{v}_{a}\right|>5.7 \mathrm{~m} \mathrm{~s}^{-1}$, as illustrated in the top horizontal axis of Fig. 5.

Next, we consider the relative importance of the current- and wind-driven terms of Eq. (6). The right vertical axis of Fig. 4 shows the coefficient $R$ [Eq. (14)] using the mean simulated velocity ratio $\left|\mathbf{v}_{a}\right| /\left|\mathbf{v}_{w}\right|=150$. This means that the role of wind drag dominates that of water drag by a factor of $R \approx 3$ for small icebergs and that wind drag becomes negligible compared to water $\operatorname{drag}(R<0.1)$ for icebergs larger than $L \approx 12 \mathrm{~km}$.

\section{2) Antarctic ICEBERg Simulations}

The results above suggest that, for large tabular icebergs as observed in Antarctica, the wind drag can be neglected to a good approximation and Eq. (6) reduces to the relation $\mathbf{v}_{i}=\mathbf{v}_{w}$, that is, large icebergs move with the surface ocean current. To demonstrate the accuracy of this approximation, we perform two more sets of simulations using the same initial conditions as those for the Antarctic simulations discussed in section $3 \mathrm{~b}$ (above). First, we approximate icebergs to move at the 

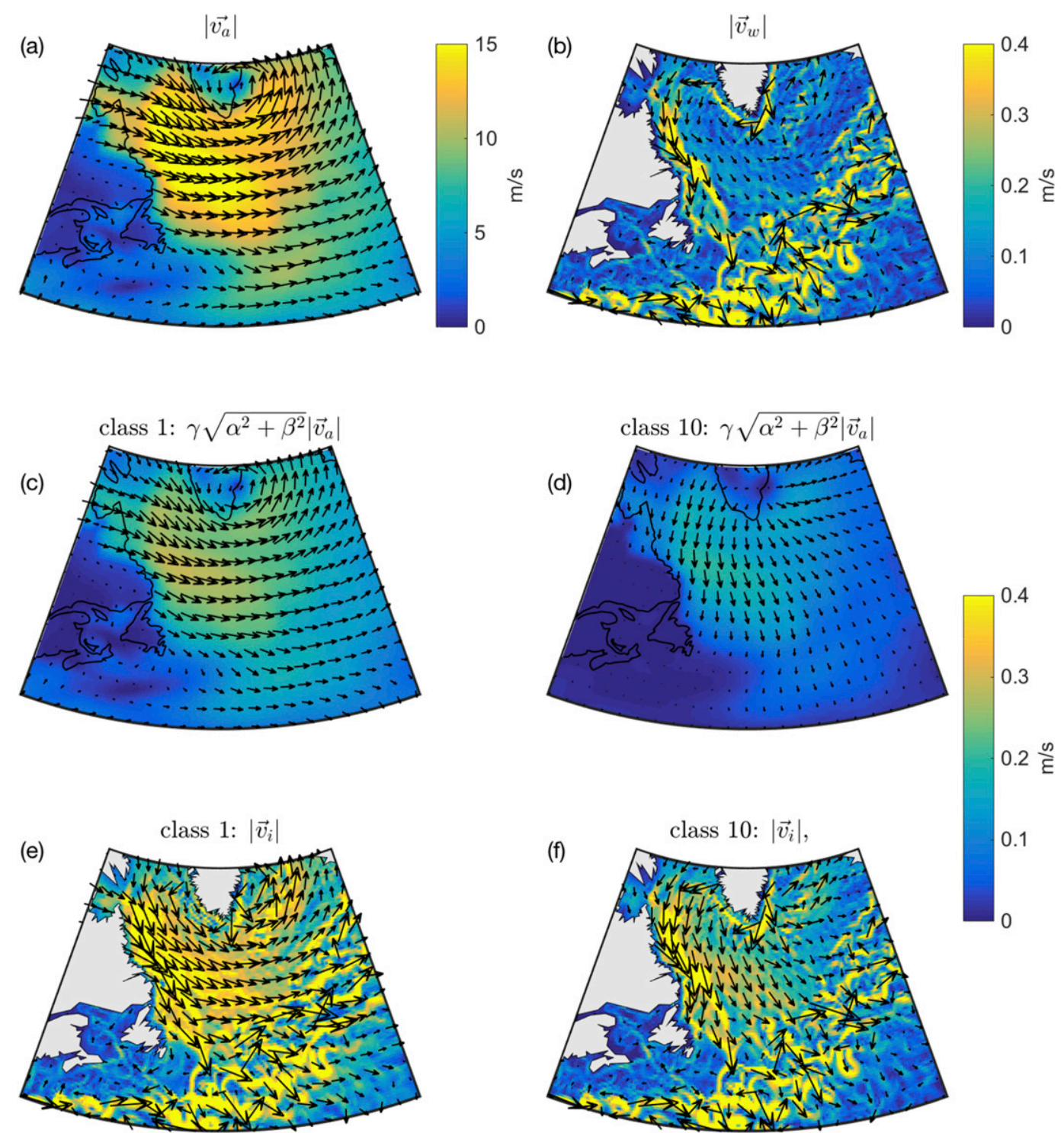

FIG. 6. Velocities in the North Atlantic from ECCO2 output averaged over the 3-day period 1-3 Jan 1993. (a) Surface wind. (b) Surface ocean current. (c) Wind-driven component of the iceberg velocity field for small (class 1) icebergs. (d) As in (c), but for large (class 10) icebergs. (e) Iceberg velocity field for small icebergs, equal to the sum of (b) and (c). (f) Iceberg velocity field for large icebergs, equal to the sum of (b) and (d). In all panels, arrows indicate the velocity field, and shading indicates the associated speed. Note that the wind field features the signature of a winter storm.

water velocity (blue trajectories in Fig. 7). Next, we instead set icebergs to move according to the $2 \%$ rule (green trajectories in Fig. 7). Whereas the icebergs with $\mathbf{v}_{i}=\mathbf{v}_{w}$ drift in close agreement with those using the full solution (red trajectories in Fig. 7), the icebergs following the $2 \%$ rule show a substantially different drift pattern because they are influenced by the strong prevailing winds around the Antarctic Peninsula. This supports our conclusion that large icebergs move approximately with the ocean currents. It should be noted that the empirical $2 \%$ rule was originally introduced based on Northern Hemisphere iceberg observations (e.g., Garrett et al. 1985; Smith and Donaldson 1987; Smith 1993), and it has typically been applied around Greenland rather than in the Antarctic.

\section{Conclusions}

We have presented an idealized iceberg drift model with an analytical solution for the velocity of icebergs 


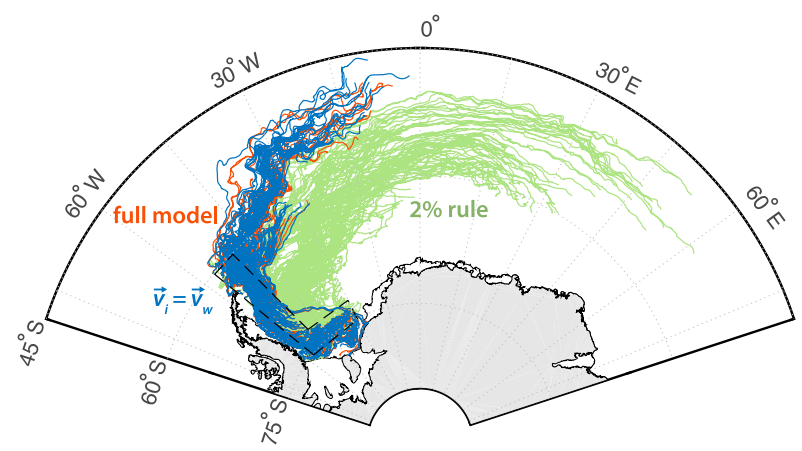

FIG. 7. Simulated Antarctic iceberg trajectories. Shown are simulations of the full analytical model (red), iceberg motion that follows the ocean currents (blue, overlaying most of the red trajectories), and iceberg motion that follows the $2 \%$ rule (green). Icebergs are released from random locations within the region indicated by the dashed polygon.

as a function of the ocean current and wind. This solution facilitates

- an improved understanding of the underlying mechanisms determining iceberg drift; and

- computationally inexpensive simulations of large numbers of iceberg trajectories.

In these simulations, the wind-driven iceberg motion dominates the ocean-driven motion approximately threefold for small icebergs $(L<200 \mathrm{~m})$, and it becomes less than $10 \%$ of the ocean-driven motion for large icebergs with $L>12 \mathrm{~km}$.

We use the model to demonstrate that in the limit of small icebergs or strong winds, icebergs drift at $\sim 2 \%$ of the surface winds relative to the water. This asymptotic result of the analytical model agrees with an empirical rule of thumb used in previous studies. However, the results highlight the limitations of this $2 \%$ rule: in the limit of large icebergs or weak winds, the wind contribution to driving the icebergs becomes negligible, and the icebergs drift with the surface ocean current. By considering trajectories computed from ECCO2 output fields, we find that these two limits approximately correspond to typical (small) Arctic icebergs and typical (large) Antarctic icebergs, respectively.

The dependence of the drift velocity regime on iceberg size can be explained through the relative importance of the drag terms compared with the Coriolis term (which includes the pressure gradient force in this representation). Since the drag terms scale with surface area $L H$, and the Coriolis term scales with volume $L^{2} H$ (assuming similar horizontal dimensions, $L \sim W$ ), the Coriolis term dominates the momentum balance [Eq. (3)] in the limit of large icebergs. This implies that $\mathbf{v}_{i}-\mathbf{v}_{w}=0$ : icebergs move with the water. On the other hand, the drag terms dominate the momentum balance
[Eq. (3)] in the limit of small icebergs. In this case, the solution is $\mathbf{v}_{i}-\mathbf{v}_{w}=\gamma \mathbf{v}_{a}$ : icebergs move at $2 \%$ of the wind velocity relative to the water.

Acknowledgments. We are grateful to Jeff Severinghaus and Ralph Keeling for helpful discussions during the development of this work. This work was supported by National Science Foundation Grant OCE-1357078. MATLAB code for the iceberg drift and decay model presented here is available online (at http://eisenman. ucsd.edu/code).

\section{APPENDIX}

\section{Iceberg Decay Representation}

Here, further details are given regarding the iceberg decay representation, which is summarized in section 2c. This is based on the thermodynamic decay model of Bigg et al. (1997), using a representation adapted from Martin and Adcroft (2010). The three dominant melt processes, (i) wind-driven wave erosion $M_{e}$, (ii) turbulent basal melt $M_{b}$, and (iii) thermal sidewall erosion from buoyant convection $M_{v}$, are represented as follows:

$$
\begin{aligned}
& M_{e}=S_{s} / 2=a_{1}\left|\mathbf{v}_{a}\right|^{1 / 2}+a_{2}\left|\mathbf{v}_{a}\right|, \\
& M_{v}=b_{1} T_{w}+b_{2} T_{w}^{2}, \\
& M_{b}=c\left|\mathbf{v}_{w}-\mathbf{v}_{i}\right|^{4 / 5}\left(T_{w}-T_{i}\right) L^{-1 / 5},
\end{aligned}
$$

where $S_{s}$ is the sea state, $a_{1}=8.7 \times 10^{-6} \mathrm{~m}^{1 / 2} \mathrm{~s}^{-1 / 2}$, $a_{2}=5.8 \times 10^{-7}, \quad b_{1}=8.8 \times 10^{-8} \mathrm{~m} \mathrm{~s}^{-1}{ }^{\circ} \mathrm{C}^{-1}, b_{2}=1.5 \times$ $10^{-8} \mathrm{~m} \mathrm{~s}^{-1}{ }^{\circ} \mathrm{C}^{-2}, \quad$ and $c=6.7 \times 10^{-6} \mathrm{~m}^{-2 / 5} \mathrm{~s}^{-1 / 5}{ }^{\circ} \mathrm{C}^{-1}$. Here, $T_{w}$ is the sea surface temperature, and $T_{i}$ is the temperature of the ice, taken to be fixed at $T_{i}=-4^{\circ} \mathrm{C}$ (El-Tahan et al. 1987). Other processes, such as surface melt, have been found to be small compared to these terms (Savage 2001) and are neglected here. The iceberg dimensions evolve as $d L / d t=d W / d t=M_{e}+M_{v}$ and $d H / d t=M_{b}$. Finally, we impose that an iceberg capsizes when its width-to-height ratio $\varepsilon \equiv W / H$ falls below a critical value $\varepsilon_{c}$ (MacAyeal et al. 2003; Wagner et al. 2017, manuscript submitted to Ocean Modell.), where

$$
\varepsilon_{c}=\sqrt{6 \frac{\rho_{i}}{\rho_{w}}\left(1-\frac{\rho_{i}}{\rho_{w}}\right)} .
$$

\section{REFERENCES}

Ballantyne, J., and D. G. Long, 2002: A multidecadal study of the number of Antarctic icebergs using scatterometer data. IEEE Int. Geosci. Remote Sensing Symp. IGARSS '02, Toronto, ON, 
Canada, Institute of Electrical and Electronics Engineers, 3029-3031, doi:10.1109/IGARSS.2002.1026859.

Bigg, G. R., M. R. Wadley, D. P. Stevens, and J. A. Johnson, 1996: Prediction of iceberg trajectories for the North Atlantic and Arctic Oceans. Geophys. Res. Lett., 23, 3587-3590, doi:10.1029/96GL03369.

$-, \ldots, \ldots$, and ——, 1997: Modelling the dynamics and thermodynamics of icebergs. Cold Reg. Sci. Technol., 26, 113135, doi:10.1016/S0165-232X(97)00012-8.

Bügelmayer, M., D. M. Roche, and H. Renssen, 2015a: How do icebergs affect the Greenland Ice Sheet under preindustrial conditions?-A model study with a fully coupled ice-sheet-climate model. Cryosphere, 9, 821-835, doi:10.5194/tc-9-821-2015.

$\longrightarrow, \ldots$, and $—, 2015 \mathrm{~b}$ : Representing icebergs in the $i$ LOVECLIM model (version 1.0) - A sensitivity study. Geosci. Model. Dev., 8, 2139-2151, doi:10.5194/gmd-8-2139-2015.

Copland, L., D. R. Mueller, and L. Weir, 2007: Rapid loss of the Ayles ice shelf, Ellesmere Island, Canada. Geophys. Res. Lett., 34, L21501, doi:10.1029/2007GL031809.

Crepon, M., M. N. Houssais, and B. Saint Guily, 1988: The drift of icebergs under wind action. J. Geophys. Res., 93, 3608-3612, doi:10.1029/JC093iC04p03608.

Death, R., M. J. Siegert, G. R. Bigg, and M. R. Wadley, 2006: Modelling iceberg trajectories, sedimentation rates and meltwater input to the ocean from the Eurasian Ice Sheet at the Last Glacial Maximum. Palaeogeogr. Palaeoclimatol. Palaeoecol., 236, 135-150, doi:10.1016/j.palaeo.2005.11.040.

Duprat, L. P. A. M., G. R. Bigg, and D. J. Wilton, 2016: Enhanced Southern Ocean marine productivity due to fertilization by giant icebergs. Nat. Geosci., 9, 219-221, doi:10.1038/ ngeo2633.

El-Tahan, M., S. Venkatesh, and H. El-Tahan, 1987: Validation and quantitative assessment of the deterioration mechanisms of Arctic icebergs. J. Offshore Mech. Arctic Eng., 109, 102108, doi:10.1115/1.3256983.

Enderlin, E. M., I. M. Howat, S. Jeong, M. J. Noh, J. H. Angelen, and M. R. Broeke, 2014: An improved mass budget for the Greenland Ice Sheet. Geophys. Res. Lett., 41, 866-872, doi:10.1002/2013GL059010.

FitzMaurice, A., F. Straneo, C. Cenedese, and M. Andres, 2016: Effect of a sheared flow on iceberg motion and melting. Geophys. Res. Lett., 43, 12 520-12 527, doi:10.1002/ 2016GL071602.

Garrett, C., J. Middleton, M. Hazen, and F. Majaess, 1985: Tidal currents and eddy statistics from iceberg trajectories off Labrador. Science, 227, 1333-1335, doi:10.1126/ science.227.4692.1333.

Gladstone, R. M., G. R. Bigg, and K. W. Nicholls, 2001: Iceberg trajectory modeling and meltwater injection in the Southern Ocean. J. Geophys. Res., 106, 19903-19915, doi:10.1029/ 2000JC000347.

Hemming, S. R., 2004: Heinrich events: Massive late pleistocene detritus layers of the North Atlantic and their global climate imprint. Rev. Geophys., 42, RG1005, doi:10.1029/ 2003RG000128.

Henderson, J., and J. S. P. Loe, 2016: The prospects and challenges for Arctic oil development. Oil Gas Energy Law J., 14 (2). [Available online at www.ogel.org/article.asp?key =3620.]

Hunke, E. C., and D. Comeau, 2011: Sea ice and iceberg dynamic interaction. J. Geophys. Res., 116, C05008, doi:10.1029/ 2010JC006588.
International Ice Patrol, 2009: What is the extreme range of iceberg locations? U.S. Coast Guard Navigation Center, accessed 25 May 2017. [Available online at https://www.navcen.uscg.gov/? pageName $=$ iipWhatIsTheExtremeRangeOfIcebergLocations.]

Jongma, J. I., E. Driesschaert, T. Fichefet, H. Goosse, and H. Renssen, 2009: The effect of dynamic-thermodynamic icebergs on the Southern Ocean climate in a threedimensional model. Ocean Modell., 26, 104-113, doi:10.1016/j.ocemod.2008.09.007.

- H. Renssen, and D. M. Roche, 2013: Simulating Heinrich event 1 with interactive icebergs. Climate Dyn., 40, 1373-1385, doi:10.1007/s00382-012-1421-1.

Joughin, I., B. E. Smith, and B. Medley, 2014: Marine ice sheet collapse potentially under way for the Thwaites Glacier Basin, West Antarctica. Science, 344, 735-738, doi:10.1126/ science.1249055.

Keghouche, I., L. Bertino, and K. A. Lisæter, 2009: Parameterization of an iceberg drift model in the Barents Sea. J. Atmos. Oceanic Technol., 26, 2216-2227, doi:10.1175/ 2009JTECHO678.1.

Kubat, I., M. Sayed, S. B. Savage, and T. Carrieres, 2005: An operational model of iceberg drift. Int. J. Offshore Polar Eng., 15, $125-131$.

Lichey, C., and H. H. Hellmer, 2001: Modeling giant-iceberg drift under the influence of sea ice in the Weddell Sea, Antarctica. J. Glaciol., 47, 452-460, doi:10.3189/172756501781832133.

MacAyeal, D. R., T. A. Scambos, C. L. Hulbe, and M. A. Fahnestock, 2003: Catastrophic ice-shelf break-up by an iceshelf-fragment-capsize mechanism. J. Glaciol., 49, 22-36, doi:10.3189/172756503781830863.

Marsh, R., and Coauthors, 2015: NEMO-ICB (v1.0): Interactive icebergs in the NEMO ocean model globally configured at eddy-permitting resolution. Geosci. Model Dev., 8, 1547-1562, doi:10.5194/gmd-8-1547-2015.

Martin, T., and A. Adcroft, 2010: Parameterizing the fresh-water flux from land ice to ocean with interactive icebergs in a coupled climate model. Ocean Modell., 34, 111-124, doi:10.1016/j.ocemod.2010.05.001.

Matsumoto, K., 1996: An iceberg drift and decay model to compute the ice-rafted debris and iceberg meltwater flux: Application to the interglacial North Atlantic. Paleoceanography, 11, 729742, doi:10.1029/96PA02712.

Menemenlis, D., J. M. Campin, and P. Heimbach, 2008: ECCO2: High resolution global ocean and sea ice data synthesis. Mercator Ocean Quarterly Newsletter, No. 31, Mercator Ocean, Ramonville-Saint-Agne, France, 13-21.

Merino, N., J. Le Sommer, G. Durand, N. C. Jourdain, G. Madec, P. Mathiot, and J. Tournadre, 2016: Antarctic icebergs melt over the Southern Ocean: Climatology and impact on sea ice. Ocean Modell., 104, 99-110, doi:10.1016/ j.ocemod.2016.05.001.

Onogi, K., and Coauthors, 2007: The JRA-25 reanalysis. J. Meteor. Soc. Japan, 85, 369-432, doi:10.2151/jmsj.85.369.

Pizzolato, L., S. E. L. Howell, C. Derksen, J. Dawson, and L. Copland, 2014: Changing sea ice conditions and marine transportation activity in Canadian Arctic waters between 1990 and 2012. Climatic Change, 123, 161-173, doi:10.1007/ s10584-013-1038-3.

Rignot, E., and P. Kanagaratnam, 2006: Changes in the velocity structure of the Greenland Ice Sheet. Science, 311, 986-990, doi:10.1126/science.1121381.

, I. Velicogna, M. R. van den Broeke, A. Monaghan, and J. Lenaerts, 2011: Acceleration of the contribution of the 
Greenland and Antarctic Ice Sheets to sea level rise. Geophys. Res. Lett., 38, L05503, doi:10.1029/2011GL046583.

Robe, R. Q., 1980: Iceberg drift and deterioration. Dynamics of Snow and Ice Masses, S. C. Colbeck, Ed., Academic Press, 211-260.

Roberts, W. H. G., P. J. Valdes, and A. J. Payne, 2014: A new constraint on the size of Heinrich events from an iceberg/ sediment model. Earth Planet. Sci. Lett., 386, 1-9, doi:10.1016/ j.epsl.2013.10.020.

Savage, S. B., 2001: Aspects of iceberg deterioration and drift. Geomorphological Fluid Mechanics, Springer, 279-318.

Schodlok, M. P., H. H. Hellmer, G. Rohardt, and E. Fahrbach, 2006: Weddell Sea iceberg drift: Five years of observations. J. Geophys. Res., 111, C06018, doi:10.1029/2004JC002661.

Silva, T. A. M., G. R. Bigg, and K. W. Nicholls, 2006: Contribution of giant icebergs to the Southern Ocean freshwater flux. J. Geophys. Res., 111, C03004, doi:10.1029/2004JC002843.

Smith, K. L. J., A. D. Sherman, T. J. Shaw, and J. Sprintall, 2013: Icebergs as unique Lagrangian ecosystems in polar seas. Annu. Rev. Mar. Sci., 5, 269-287, doi:10.1146/annurev-marine-121211-172317.

Smith, S. D., 1993: Hindcasting iceberg drift using current profiles and winds. Cold Reg. Sci. Technol., 22, 33-45, doi:10.1016/ 0165-232X(93)90044-9.

__ and E. G. Banke, 1983: The influence of winds, currents and towing forces on the drift of icebergs. Cold Reg. Sci. Technol., 6, 241-255, doi:10.1016/0165-232X(83)90045-9.

, and N. R. Donaldson, 1987: Dynamic modelling of iceberg drift using current profiles. Canadian Tech. Rep. of Hydrography and Ocean Sciences 91, 133 pp.

Stern, A. A., and Coauthors, 2015: Wind-driven upwelling around grounded tabular icebergs. J. Geophys. Res. Oceans, 120, 5820-5835, doi:10.1002/2015JC010805.
- A. Adcroft, and O. Sergienko, 2016: The effects of Antarctic iceberg calving-size distribution in a global climate model. J. Geophys. Res. Oceans, 121, 5773-5788, doi:10.1002/ 2016JC011835.

Stokes, C. R., and Coauthors, 2015: On the reconstruction of palaeo-ice sheets: Recent advances and future challenges. Quat. Sci. Rev., 125, 15-49, doi:10.1016/ j.quascirev.2015.07.016.

Tournadre, J., N. Bouhier, F. Girard-Ardhuin, and F. Remy, 2016: Antarctic icebergs distributions 1992-2014. J. Geophys. Res. Oceans, 121, 327-349, doi:10.1002/2015JC011178.

Turnbull, I. D., N. Fournier, M. Stolwijk, T. Fosnaes, and D. McGonigal, 2015: Operational iceberg drift forecasting in northwest Greenland. Cold Reg. Sci. Technol., 110, 1-18, doi:10.1016/j.coldregions.2014.10.006.

Unger, J. D., 2014: Regulating the Arctic gold rush: Recommended regulatory reforms to protect Alaska's Arctic environment from offshore oil drilling pollution. Alaska Law Rev., 31, 263294. [Available online at http://scholarship.law.duke.edu/alr/ vol31/iss $2 / 8$.]

Vernet, M., and Coauthors, 2012: Islands of ice: Influence of freedrifting Antarctic icebergs on pelagic marine ecosystems. Oceanography, 25, 38-39, doi:10.5670/oceanog.2012.72.

Wagner, T. J. W., and Coauthors, 2014: The "footloose" mechanism: Iceberg decay from hydrostatic stresses. Geophys. Res. Lett., 41, 5522-5529, doi:10.1002/2014GL060832.

Weeks, W. F., and M. Mellor, 1978: Some elements of iceberg technology. Cold Regions Research and Engineering Laboratory Rep. 78-2, 37 pp.

Wiersma, A. P., and J. I. Jongma, 2010: A role for icebergs in the 8.2 ka climate event. Climate Dyn., 35, 535-549, doi:10.1007/ s00382-009-0645-1. 